\title{
$O$ estresse do professor acentuado pela precariedade das condições acústicas das salas de aula
}

\author{
Maria Lúcia Gondim da Rosa Oiticica (UFAL) mloiticica@hotmail.com \\ Maria de Lourdes Barreto Gomes (UFPB) marilu@producao.ct.ufpb.br
}

\begin{abstract}
Resumo
Estudos recentes orientam para os cuidados que se deve ter com o estresse a curtos e longos prazos. O estresse em longo prazo pode provocar reações crônicas no indivíduo. O desgaste, o esgotamento, a ruptura total dos limites, referem-se a reações do estresse crônico que exigem a necessidade urgente da intervenção terapêutica de profissional de saúde. Em pesquisa nos USA, o professor está entre os profissionais que apresentam alto índice das reações do estresse crônico. O presente trabalho avaliou dois estabelecimentos de ensino distintos: público e privado, na cidade de Maceió; com o objetivo de registrar o nível de pressão sonora - $d b(A)$, ao qual os professores são obrigados a conviver no desenrolar de suas atividades de ensino. Verificou-se assim que, seja qual for o contexto em que os estabelecimentos de ensino estejam inseridos: públicos ou privados, o professor participa das precárias condições acústicas das salas de aula, agravadas pela intensa convivência com o ruído externo, o qual é considerado um grande causador de desconforto e estresse para os professores.
\end{abstract}

Palavras-chave: Estresse, Professor, Precárias condições acústicas.

\section{Introdução}

As relações entre o trabalho e a saúde dos trabalhadores vêm ganhando uma nova dimensão nos últimos anos dentro do processo de globalização ou mundialização que, segundo alguns autores, se inicia no século XXI ou no terceiro milênio da Era Cristã.

As condições dessa nova ordem mundial, desse novo modo de produzir e comercializar, aparecem refletidas sobre o trabalho em si, nos níveis de emprego, no meio ambiente e nos níveis de saúde das populações e dos trabalhadores, em particular.

Entre alguns impactos sobre o mundo de trabalho podem ser destacados: a introdução de tecnologias, particularmente da automação e da robótica substituindo o trabalho do homem; o declinio da atividade de manufactura e o crescimento do setor de serviços; a introdução de novos processos produtivos de produção e gestão do trabalho, gerando novos riscos para a saúde e o meio ambiente; as proliferações de pequenas unidades de produção com maior dificuldade para sua organização; aumento da intensidade e duração do trabalho, levando ao aumento de estresse e das doenças dele decorrentes; aumento do trabalho realizado no domicílio, do trabalho em tempo parcial e sazonal, levando à precarização do trabalho; diminuição dos níveis de remuneração e pagamento pelo trabalho realizado.

Com isto, pode-se observar, uma verdadeira revolução na natureza do trabalho e na percepção de seu papel pelas quencias onde a difusão das novas tecnologias de produção associadas às novas técnicas de gestão provocam e exigem a recuperação da inteligencia da produção. Portanto, torna-se mais acentuada a exigência de uma maior qualificação da força do trabalho, maior escolaridade dos trabalhadores, como tambem exigem alternativas ou estratégias de gestão que levem à cooperação por parte dos trabalhadores. 
Neste cenário, a responsabilidade pela formação das pessoas desde a educação básica torna-se uma tarefa de maior relevância, uma vez que se constitui o primeiro passo para a formação das pessoas, que no futuro atuarão no mercado de trabalho. Mesmo com o grande avanço da tecnologia e as mudanças que vêm se processando nas atividades gerenciais, a presença do professor em sala de aula é uma prática essencial para conduzir o processo de ensino e aprendizagem para a formação do educando.

Considerando as exigências do mundo competitivo em que as escolas estão inseridas, do professor é cobrado conhecimento em constante atualização, rápida adaptação aos valores sociais que se renovam a cada dia, entre outros. Entretanto, a realidade das escolas, particulares ou públicas, majoritariamente, não oferecem condições suficientes para as práticas educacionais e formacionais exigidas, quer seja em termos de materiais didáticos, recursos audiovisuias e sobretudo o ambiente fisico das salas de aulas. Além disso, o salário qué não é condizente com a responsabilidade do educador, contribuindo para a insatisfição, atuando também no nível de estresse.

Desta forma, pode-se dizer que o professor encontra-se entre os profissionais que mais estão imbuidos pelo estresse. Segundo pesquisa feita nos USA, por Moracco, D'Ariengo (apud REINOLD, 1995), o absenteísmo do professor é devido, em grande parte, ao estresse ocupacional, $52 \%$ declararam que não escolheriam essa carreira novamente.

No caso brasileiro, segundo Codo, W. \& Sampaio, "o estresse do professor parece estar relacionado ao salario não digno, à precariedade das condições de trabalho, ao alto volume de atribuições burocráticas, ao elevado número de turmas assumidas e de alunos por sala, ao mau comportamento desses alunos, ao treinamento inadequado do professor diante de novas situações e emergências da época. O professor sofre, ainda, com pressões de tempo, pressões dos pais dos alunos e de suas preocupações pessoais extra-escola.

Em estudo mencionado por Reinhold, através do depoimento de professores, seis foram as fontes desse estresse:

a) Ter classes com muitos alunos;

b) Trabalhar com alunos desinteressados pelas atividades de classe;

c) Achar que alguns alunos indisciplinados ocupam demais tempo em deprejuízo de outro;

d) Ter alunos na classe que conversam e/ou brincam o tempo todo;

e) Trabalhar com uma classe onde as capacidades dos alunos são muito diferentes entre si;

f) Sentir que há falta de apoio dos pais para resolver problemas de indisciplina.

Pode-se observar que, dentre estas fontes de estresse do professor, as condições acústicas do ambiente de trabalho podem ser co-autoras de tamanha variedade de estresse. Neste contexto, este trabalho apresenta os resultados de uma avaliação realizada numa escola pública e privada, comprovando que o estresse do professor no atual mundo do trabalho é intensificado diante das condições acústicas do espaço físico de trabalho. Para tal, procurou-se verificar que a interferência dos ruídos externos em sala de aula provenientes do desenvolvimento das cidades, tornaram certas escolas, que no passado encontravam-se com implantações urbanisticas aceitáveis dos seus serviços, passaram a ser mero palco de insalubridade para o desenvolvimento das atividades acadêmicas, uma vez que o tráfego intenso tomou conta da sua circunvizinhança. Isto comprova que as nossas escolas públicas e privadas, onde a climatização é essencialmente natural, necessitam que seu espaço físico seja repensado, uma vez que que é comum a interferência do tráfego nestes espaços, acentuando ainda mais o nível de estresse do professor em sala de aula, inibindo o aproveitamento e o rendimento de professores e alunos. 


\section{Condições acústicas em sala de aula}

A acústica é uma área da física extremamente abrangente e atua em diversas áreas da ciência. A acústica Arquitetônica ocupa-se de duas áreas que, apesar de bastante próximas, merecem ser referenciadas separadamente:

a) Defesa do ruído:

Consiste no estudo das condições acústicas aceitáveis nas construções, ocupando-se em isolar o ruído externo e promovendo o conforto do usuário.

b) Controle dos sons nos recintos:

Sua função é melhorar as condições de cada sala, considerando-a isenta do barulho externo. Estuda a forma e tratamento dos ambientes de modo a torná-lo acusticamente satisfatório.

A necessidade de avaliar salas de aula cujos ambientes são relativamente simples do ponto de vista de sua volumetria e espacialidade, muito embora a sua função seja de extrema importância, pois são nesses espaços que são transmitidos conhecimentos, onde alunos e professores estão inseridos.

O ideal das salas de aula, ou qualquer construção é evitar os possíveis problemas acústicos, Salas com desfavoráveis condições acústicas colaboram com uma série de problemas. Pode-se dizer que dentre eles, esta inserido o estresse do professor em sala de aula. A comunicação entre professor e aluno é a principal caracteristíca de uma sala de aula, no entanto, esse é um dos problemas que mais afetam as escolas, prejudicando e dificultando de diversas formas o aprendizado.

Segundo Picard e Bradley (1999), referindo-se à uma pesquisa realizada nos Estados Unidos, as salas de aula são considerados locais extremamente barulhentos, onde os estudantes com audição normal conseguem entender apenas $66 \%$ das palavras pronuciadas pelos professores.

Erdreich, e Moran (1999) afirmam que as crianças nos EUA apresentam problemas de audição ou de aprendizado, além de estarem enfrentando dificuldades para conseguir ouvir seus professores devido à baixa qualidade acústica de salas de aula.

Percebe-se que os problemas nas escolas são os mesmos, independente de sua localização. $\mathrm{O}$ elevado nível de ruído externo, materiais, equipamentos e aberturas inadequadas em salas de aula colaboram para que níveis de estresse de alunos e/ou professores sejam encontrados.

A Norma Brasileira 10152 (ABNT) estabelece os níveis máximos de ruído para cada ambiente. Esta norma estabelece critérios e métodos para avaliar conforto acústico, quanto ao ruído ambiente, em recinto de uma edificação. Sabendo-se que o nível de ruído em uma sala de aula deve ser de até $45 \mathrm{db}(\mathrm{A})$, o nível da voz humana é de $65 \mathrm{db}(\mathrm{A})$ e uma voz alta (sem gritar) chega a $75 \mathrm{db}(\mathrm{A})$, essa diferença entre o nível da fala e o ruído da sala é responsável pela inteligibilidade das palavras em sala de aula. Quanto maior esta diferença, melhor a compreensão do aluno e menor o nível de estresse do professor, uma vez que sua preocupação e esforço físico em transmitir seu conhecimento tambem é reduzida. Esta relação que é chamada de relação Sinal/Ruído deve ter valores mínimos entre 10 e 15 db(A). Uma sala de aula com estes valores, pode-se dizer que as condições acústicas de compreensão (inteligibilidade) já não são tão satisfatórias.

\section{Reações fisiológicas correlacionadas com níveis de ruído ambiente}

A psicoacústica é uma ciência relativamente antiga que associa a psicologia com a percepção auditiva em busca do que, no jargão da engenharia, se chama de qualidade sonora. Como a capacidade para ouvir sons (ruídos) varia bastante para pessoa, a psicoacústica quantifica as 
sensações auditivas de volume, som (mais ou menos agudo) e aspereza para torná-lo mais agradável.

Segundo Spoendlin (1976), o ruído atinge diferentemente as estruturas do orgão de corti, que é a estrutura receptora auditiva. Aqueles que são intensos de impacto tendem a produzir lesões mecânicas, com consequente processo degenerativo. Os ruídos contínuos e prolongados originam alterações mais para exaustão metabólica das células sensoriais e seus cílios. A psicoacústica estuda as sensações auditivas para estímulos sonoros.

Como efeitos extra-auditivos, Kitamura (1995) destaca as reações generalizadas ao estresse, reações físicas tais como: alterações da função intestinal e cardiovascular, alterações mentais e emocionais, que podem se manifestar por irritabilidade, ansiedade, excitabilidade, insônia etc e problemas específicos.

Os ambientes acústicos, ao receberem certos níveis de ruído, db(A), fazem com que existam reações fisiológicas por seus usuários. O limite de ruído a ser avaliado nos ambientes é baseado na NRB 10152 em função da tarefa desenvolvida neste ambiente. De acordo com este limite pode-se classificar as reações fisiológicas em tres categorias:

\section{a) Categoria SAUDÁVEL:}

A tabela 1, abaixo, descrimina que o ruído ainda é considerável saudável, quando seu nível de pressão sonora não ultrapasse a recomendação da NRB 10152 para determinado ambiente. No caso em estudo, podemos considerar uma sala de aula com níveis de ruído saudáveis quando a mesma não ultrapassa indíces acima de $45 \mathrm{db}(\mathrm{A})$. As reações fisiológicas nesta escala de ruído não indicam maiores pertubações nos ambientes sendo os mesmos consideráveis salubres.

\begin{tabular}{|c|c|c|c|c|}
\hline & \multirow{2}{*}{$\begin{array}{l}\text { Ruído } \\
\text { dB(A) }\end{array}$} & \multicolumn{2}{|c|}{ Ambiente acústico } & \multirow{2}{*}{ Reações Fisiológicas } \\
\hline & & Limites & Exemplos & \\
\hline \multirow{3}{*}{ 离 } & 35 & $\begin{array}{l}\text { Limite de conforto para } \\
\text { hospitais, apartamentos, } \\
\text { dormitórios, bibliotecas, } \\
\text { cinemas, salas de conferência, } \\
\text { sala de projetos (NRB10152). }\end{array}$ & $\begin{array}{l}\text { Sussuro da voz } \\
\text { humana }\end{array}$ & $\begin{array}{l}\text { Início do incômodo do sono, com } \\
\text { moudanças (aumentos) dos } \\
\text { estágios supeficiais do sono. } \\
\text { Nível de bem-estar noturno } \\
\text { (WHO). Início das reações } \\
\text { vegetativas. }\end{array}$ \\
\hline & 40 & $\begin{array}{l}\text { Indicado para salas de aula, para } \\
\text { sala de hospitais. Limite de } \\
\text { conforto para salas de aula, } \\
\text { laboratórios, restaurantes, salas } \\
\text { de estar, igrejas e templos } \\
\text { (NBR10152). Nível máximo de } \\
\text { ruído diurno indicado para } \\
\text { residências. }\end{array}$ & $\begin{array}{l}\text { Música suave } \\
\text { Ambiente tranquilo }\end{array}$ & $\begin{array}{l}\text { Ambiente próprio para } \\
\text { comunicação e ensino, com alto } \\
\text { grau de compreensão. }\end{array}$ \\
\hline & 45 & $\begin{array}{l}\text { Nível máximo de ruído diurno } \\
\text { indicado para residências } \\
\text { (NRB10151). } \\
\text { Limite de conforto para áreas de } \\
\text { serviços, circulação, corredores, } \\
\text { portarias, recepção, salas de } \\
\text { computadores (NRB10152). }\end{array}$ & $\begin{array}{l}\text { Ruído de um } \\
\text { refrigerador, voz } \\
\text { humana em baixo } \\
\text { volume, sala de estar } \\
\text { tranquila. }\end{array}$ & $\begin{array}{l}\text { Nível que causa diminuição no } \\
\text { tempo total do sono, grande } \\
\text { estágio V do sono. }\end{array}$ \\
\hline
\end{tabular}

Tabela 1 - Reações fisiológicas correlacionadas com níveis de ruído ambiente - SAUDÁVEL 


\section{b) Categoria TOLERÁVEL;}

Nesta tabela 2 abaixo, pode-se observar que os valores de ruídos dão início no limite de conforto acústico e vão até o nível da voz humana alterada. Seus valores vão entre 50 a 65 $\mathrm{db}(\mathrm{A})$. Pode-se observar que nesta faixa algumas reações fisiológicas como perda de concentração, início de estresse leve e aumento da frequência cardíca já se apresentam. Quanto aos limites de ruído, convém ressaltar que os níveis de pressão sonora já se encontram fora dos padrões desejáveis em salas de aula. Entes índices já dizem respeito a ambientes urbanos comerciais.

\begin{tabular}{|c|c|c|c|c|}
\hline & \multirow{2}{*}{$\begin{array}{l}\text { Ruído } \\
\text { dB(A) }\end{array}$} & \multicolumn{2}{|c|}{ Ambiente acústico } & \multirow{2}{*}{ Reações Fisiológicas } \\
\hline & & Limites & Exemplos & \\
\hline \multirow{4}{*}{ 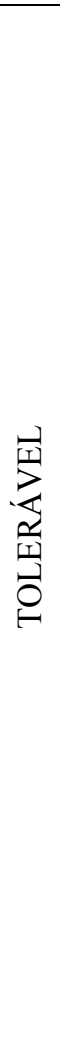 } & 50 & $\begin{array}{l}\text { Limite para sala de música de } \\
\text { fundo. Limite de conforto para } \\
\text { salas de impressão, xerox, } \\
\text { impressoras (NRB10152). }\end{array}$ & $\begin{array}{l}\text { Ruas tranquilas sem } \\
\text { tráfego, canto alto de } \\
\text { pássaros, ruído de } \\
\text { ventilador. }\end{array}$ & $\begin{array}{l}\text { Limite de conforto auditivo, nível } \\
\text { limite para o bem-estar diurno. }\end{array}$ \\
\hline & 55 & $\begin{array}{l}\text { Limite indicado para pátios } \\
\text { escolares, limite para regiões } \\
\text { residenciais urbanas } \\
\text { (NRB10151). }\end{array}$ & $\begin{array}{l}\text { Nível da voz humana } \\
\text { (baixa), pequena loja } \\
\text { tranquila. }\end{array}$ & $\begin{array}{l}\text { Início do estresse leve que excita } \\
\text { o SNC autônomo simpático, } \\
\text { produzindo desconforto auditivo, } \\
\text { maior vigilância e agitação, } \\
\text { início da perda de concentração. }\end{array}$ \\
\hline & 60 & & $\begin{array}{l}\text { Restaurante } \\
\text { tranquilo. Nível da } \\
\text { voz humana normal. }\end{array}$ & $\begin{array}{l}\text { Aumenta } 25 \% \text { a probabilidade de } \\
\text { uma pessoa acordar. Aumento da } \\
\text { frequência cardíaca. Aumento da } \\
\text { taza de excreção da adrenalina. } \\
\text { Início da perda da capacidade de } \\
\text { cálculo. Perda de concentração. } \\
\text { Retardo nas respostas e } \\
\text { conclusões. Início da mudança do } \\
\text { limiar auditivo para pessoas } \\
\text { muito sensíveis. }\end{array}$ \\
\hline & 65 & $\begin{array}{l}\text { Limite de ruído para regiões } \\
\text { urbanas comerciais (NRB10151) }\end{array}$ & $\begin{array}{l}\text { Nível da voz humana } \\
\text { alterada. }\end{array}$ & $\begin{array}{l}\text { Início da liberação de } \\
\text { noradrenalina. Início da } \\
\text { insensibilização das pessoas pelo } \\
\text { efeito anestésico. Pessoas } \\
\text { barulho-dependentes pela } \\
\text { liberação de drogas psicotrópicas } \\
\text { pelo cérebro. }\end{array}$ \\
\hline
\end{tabular}

Tabela 2 - Reações fisiológicas correlacionadas com níveis de ruído ambiente - TOLERÁVEL

\section{c) Categoria INSALUBRE;}

Nesta categoria pode-se encontrar indices maximos de ruído para areas industrias. Sua escala de pressão sonora encontra-se acima de $70 \mathrm{db}(\mathrm{A})$. Pode-se encontrar a presença de reações fisiológicas como estresse degenerativo, infarto, perdas de audição e problemas relacionados com a voz humana prejudicando as cordas vocais. Todas estas reações são acarretadas pela grande intensidade de ruído. A tabela 3 abaixo, esclarece os limites de ruído e os corelacionando-os. 


\begin{tabular}{|c|c|c|c|c|}
\hline & \multirow{2}{*}{$\begin{array}{l}\text { Ruído } \\
\text { dB(A) }\end{array}$} & \multicolumn{2}{|c|}{ Ambiente acústico } & \multirow{2}{*}{ Reações Fisiológicas } \\
\hline & & Limites & Exemplos & \\
\hline \multirow{5}{*}{ 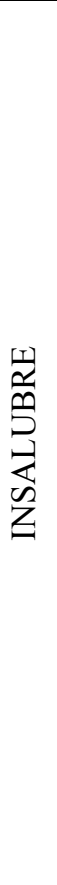 } & 70 & $\begin{array}{l}\text { Nível máximo de áreas } \\
\text { industriais (NRB10151) }\end{array}$ & $\begin{array}{l}\text { Voz de professor } \\
\text { ministrando aulas. } \\
\text { Ruas de tráfego bem } \\
\text { intenso até } \\
1000 \text { veículos/hora. } \\
\text { Nível de fala poluída } \\
\text { por ruído. } \\
\text { Inteligibilidade } \\
\text { limite. }\end{array}$ & $\begin{array}{l}\text { Estresse degenerativa. Infarto e } \\
\text { anestesia por endorfina. Início de } \\
\text { problemas nas cordas vocais. }\end{array}$ \\
\hline & 75 & & $\begin{array}{l}\text { Ruído de uma } \\
\text { máquina de escrever } \\
\text { e automóveis. }\end{array}$ & $\begin{array}{l}\text { Limite para início de problemas } \\
\text { auditivos permanentes. }\end{array}$ \\
\hline & 80 & $\begin{array}{l}\text { Limite de esposição de } \\
\text { trabalhadores sem proteção em } \\
\text { alguns países (Europa) }\end{array}$ & $\begin{array}{l}\text { Ruído de ruas de } \\
\text { trânsito intenso, } \\
\text { ambientes industriais } \\
\text { e arredores de } \\
\text { aeroportos. }\end{array}$ & \\
\hline & 85 & $\begin{array}{l}\text { Limite do Ministério do } \\
\text { Trabalho para jornada de } 8 \mathrm{~h}\end{array}$ & $\begin{array}{l}\text { Nível de aspirador de } \\
\text { pó, toque do telefone } \\
\text { e do metrô. }\end{array}$ & $\begin{array}{l}\text { Início da perda de audição } \\
\text { induzida por ruído (PAIR), } \\
\text { segundo o MTB. }\end{array}$ \\
\hline & 90 & $\begin{array}{l}\text { Limite do Ministério do } \\
\text { Trabalho para jornada de } 4 \mathrm{~h}\end{array}$ & $\begin{array}{l}\text { Nível médio em } \\
\text { discotecas. }\end{array}$ & $\begin{array}{l}\text { Nível limite para atividade de } \\
\text { lazer com exposição de } 4 \mathrm{~h} \text {. }\end{array}$ \\
\hline
\end{tabular}

Tabela 3 - Reações fisiológicas correlacionadas com níveis de ruído ambiente - INSALUBRE

\section{Metodologia}

Visando averiguar as condições acústicas em sala de aula e tendo como objetivo avaliar a reação fisiológica de estresse do professor, o presente trabalho foi realizado em duas escolas: pública e privada localizadas na cidade de Maceió-AL. A escolha destas escolas procedeu-se devido ambas serem próximas (obtinham uma mesma rua em comum) e tinham características espaciais das salas de aula semelhantes.

Para avaliação das condições acústicas das salas de aula foram realizadas medições com a utilização de um analisador sonoro (decíbelímetro) da Marca Lutron, código 5L-400I digital, para serem mensurados os níveis de pressão sonora. Procurou-se levantar varias medições, para obter o nivel de pressão equivalente dentro da sala de aula, em cujo ambiente era considerado crítico. As medições foram feitas com as salas de aula cheias, porém com alunos supostamente em silêncio.

\subsection{Características das escolas:}

\subsubsection{Escola Pública:}

As escolas públicas, geralmente, são construções simples, onde os recursos acústicos para melhoria dos espaços físicos das salas de aula são praticamente inexistentes. A escola em questão foi construída na década de 40, sendo alvo de algumas reformas no decorrer dos anos, tais como: mudança de revestimento, altura do pé-direito, entre outras, para adequação aos padrões dos demais projetos mais recentes desenvolvidos pelas Secretária de Educação Municipal e Estadual, muito embora nenhuma preocupação foi dada referenciando uma melhora nas suas condições acústicas. O terreno onde está situada a escola encontra-se em uma área com grande influência do ruído externo, principalmente tráfego de veículos. Esta escola se apresenta configurada como uma "ilha", pois está cercada de vias, hoje, de trânsito 
rápido e de grande fluxo. O ruído externo em salas de aulas esta presente e foi considerado como o maior causador de desconforto, prejudicando a audibilidade das palavras, desviando a atenção dos alunos durante atividades e causando esforço mental excessivo pelos professores ao cumprimento de suas atividads de ensino.

\subsubsection{Escola Privada:}

As escolas privadas, por serem instituições independentes, cujos recursos financeiros podem ser facilitadores para obtenção da qualidade dos seus espaços físicos, faz com que as mesmas possam fazer investimentos, se assim o quiserem, a fim de evitar possíveis problemas acústicos. A escola avaliada possui caracteristicas arquitetônicas simples, semelhantes quanto à espacialidade e volumetria com a escola pública, já que ambas obedecem à legislação da Secretaria de Educação Municipal e Estadual. Esta escola foi construída na decada de 60, passando também por varias reformas, mas nenhuma com maiores preocupações em combater os problemas acústicos de suas salas de aulas. Esta escola, em sua distribuição física espacial, encontra-se com suas salas de aulas voltadas para uma via secundária, de tráfego não muito intenso e sua área administrativa voltada para uma rua de trafégo intenso. Convém ressaltar que nesta mesma rua de trafégo intenso também está localizada a escola pública investigada.

\subsection{Levantamento e análise dos dados}

Com o objetivo de verificar as condições acústicas nas salas de aula em dois estabelecimentos de ensino: escola pública e privada, buscou-se assim mensurar os níveis de pressão sonora nestes ambientes. Como as salas de aula são locais onde as atividades profissionais dos professores são desenvolvidas, medições foram feitas em ambas as escolas com janelas abertas em hórario considerado de tráfego normal (fora do horário de pico) e com as salas de aula com 100\% de ocupação. No momento das medições, as salas de aula, apesar de ocupadas, encontravam-se com o professor em silêncio, apenas observando os alunos.

Os dados de níveis de pressão sonora mensurados nesta pesquisa podem ser observados na tabela 4 abaixo:

\begin{tabular}{c|c|c|c|c|c}
\hline & \multicolumn{2}{|c|}{ Ruído db(A) } & Sinal db(A) & \multicolumn{2}{c}{$\begin{array}{c}\text { Relação } \\
\text { Sinal/ruído }\end{array}$} \\
\hline \multirow{2}{*}{$\begin{array}{c}\text { Nível de pressão } \\
\text { sonora }-\mathrm{db}(\mathrm{A})\end{array}$} & Escola pública & Escola privada & Nível voz humana & \multicolumn{2}{c}{ Escola } \\
\cline { 2 - 6 } & 80 & 68 & 65 a 75 & -5 & 7 \\
\hline
\end{tabular}

Tabela 4 - Medições do niveis de pressão sonora: $\mathrm{db}(\mathrm{A})$ e a comparação da relação sinal/ruído

De acordo com a tabela 4 acima dos dados mensurados em sala de aula em ambas as escolas, pode-se observar que:

- Tanto as escolas públicas e privadas encontram-se com elevados índices de níveis de pressão sonora, $\mathrm{db}(\mathrm{A})$, indíces de ruído insalubres;

- Que os professores convivem com elevados índices de pressão sonora, os quais os conduzem a apresentação do ínicio de estresse leve e estresse degenerativo;

- Para o cumprimento do bom desempenho de suas atividades, o nível de estresse do professor é acentuado pelas dificuldades encontradas em sala de aula, provenientes dos elevados índices de ruído, provenientes da baixa relação sinal/ruído;

- Presença de outras reações fisiológicas provenientes do alto índice de ruído, tais como: retardo de respostas e conclusões, início da insensibilização das pessoas pelo efeito anestésico e perda de concentração. Reações estas que podem acentuar o nível de estresse do professor; 
- Desgaste das cordas vocais do professor por conta do alto índice de ruído, provocando a preocupação da transmissão dos seus conhecimentos, tendo como consequência o estresse.

Diante da tamanha quantidade de problemas acarretados pelo impacto do ruído dentro das salas de aulas, pode-se dizer que o ruído é, sem sombra de dúvidas, um grande causador de desconforto nas salas de aula. Desta forma, as salas de aula mereceriam ser melhor avaliadas nos projetos educacionais, com a necessidade da melhora das condições acústicas, pois ao se combater o ruído, daria melhores condições de trabalho para os professores, e consequentemente o seu nível de estresse poderia ser amenizados.

\section{Conclusão}

Através das medições realizadas, pode-se observar que o professor está inserido dentro de ambientes estressantes e insalubres. A profissão do magistério é uma atividade onde costumase encontrar pessoas apaixonados pela arte de ensinar. Esta paixão, imbuida pelas insalubres condições acústicas dos ambientes de trabalho, levam o professor a cada vez mais ser precionado ao cumprimento de suas tarefas e com isto exigindo um esforço sobre humano para serem desenvolvidadas suas atividades profissionais. $\mathrm{O}$ estresse é a condição adaptativa do organismo e do psiquico humano funcionando a sua maneira, onde possíveis doenças psicossomáticas podem ser desenvolvidas como consequência de um modo errado de viver. Para tal, maior atenção deve ser dada aos espaços educacionais, exigindo-se um melhor controle das condições acústicas das salas de aula, colaborando para a redução do nível de estresse do professor, pois a redução dos níveis de pressão sonora possibilitam uma melhor assimilação de professores e alunos e, consequentemente, melhor desempenho das atividades de ensino-aprendizagem desenvolvidas na sala de aula.

\section{Referências}

ASSOCIAÇÃO BRASILEIRA DE NORMAS TÉCNICAS; ABNT ; Norma NBR 10152 ; Níveis de Ruído para conforto acústico ( NB 95 ); 1990.

CODO W.; SAMPAIO, J. J. (1995) - O sofrimento psíquico nas organizações. Martins Fontes. São Paulo.

DUARTE, E. de A. C. Avaliação das condições acústicas em salas de aula em função da variação de revestimentos e de aberturas. Maceió-AL: UFAL, 2003. Trabalho Final de Graduação, 2003.

FERNANDES, J. C. Acústica e ruído. Bauru-SP: UNESP. Apostila. 1999.

GRANDJEAN, E. (1998) - Manual de Ergonomia: adaptando o trabalho ao homem. Bookman. Porto Alegre.

LIMA, R. de - O professor e o estresse. Revista Universidade e Sociedade, ano 13, n. 17, p.35-39.

MOURA, M. B. Acústica: condições acústicas das salas de aula da Escola Estadual Tavares Bastos. MaceióAL: UFAL, 2004. Trabalho Final de Graduação, 2004.

REINHOLD, H. D. (1995) - Fontes e sintomas do estresse ocupacional do professor. Revista de Psicologia / PUCCAMP, n.02 e 03, ago/dez. 